Canadian

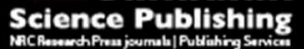

Canadian Journal of Civil Engineering Revue canadienne de génie civil

\title{
Air Pressure Drop in a Penstock during the Course of Intake-Gate Closure
}

\begin{tabular}{|r|l|}
\hline Journal: & Canadian Journal of Civil Engineering \\
\hline Manuscript ID & cjce-2016-0321.R1 \\
\hline Manuscript Type: & Article \\
\hline Date Submitted by the Author: & 12 -Sep-2016 \\
\hline Complete List of Authors: & $\begin{array}{l}\text { Huard, Michel-Olivier; Concordia University, Building, Civil and } \\
\text { Environmental Engineering } \\
\text { Li, S. Samuel; Concordia University, Building, Civil and Environmental } \\
\text { Engineering }\end{array}$ \\
\hline Keyword: & $\begin{array}{l}\text { environmental < MANUSCRIPT CLASSIFICATION, computational methods }< \\
\text { type of paper to review, english only < type of paper to review, fluid mech } \\
\text { \& hydrodyn < Hydrotechnical Eng. }\end{array}$ \\
\hline
\end{tabular}

SCHOLARONE ${ }^{m}$

Manuscripts 


\title{
Air Pressure Drop in a Penstock during the Course of Intake-Gate Closure
}

\author{
Michel-Olivier Huard ${ }^{1}$ and S. Samuel $\mathrm{Li}^{2}$ \\ ${ }^{1}$ Graduate Student, Department of Building, Civil and Environmental Engineering \\ Concordia University \\ 1455 de Maisonneuve Boulevard West, Montreal, QC H3G 1M8, Canada \\ ${ }^{2}$ Associate Professor, Department of Building, Civil and Environmental Engineering \\ Concordia University \\ 1455 de Maisonneuve Boulevard West, Montreal, QC H3G 1M8, Canada
}

Corresponding author: S. Samuel Li

Address: 1455 de Maisonneuve Boulevard West, Montreal, QC H3G 1M8, Canada

Phone number: (514) 8482424 ext. 3033

E-mail address: sam.li@concordia.ca 


\begin{abstract}
In urgent situations, the intake gates of a hydroelectric power generating station must be closed to stop the inflow of water to the station's penstock. During the course of gate closure, the air pressure in the penstock can drop drastically, posing safety risks. This paper aims to develop reliable methods for predicting pressure drop. The methods consider time-dependent water inflow, air entrainment in the penstock, air-water outflow from the penstock, and airflow down the air vent system. The methods are used to calculate time-dependent flow and pressure drop for two stations in Quebec, producing results in good comparison with field measurements. In the penstock, water jet intensifies in the first half of the closure time period, whereas air pressure drops in the last one third of the time period. Air entrainment is an important cause of pressure drop. The methods are useful for planning air-vent upgrades and safe closure operations.
\end{abstract}

Key words: penstock, air pressure drop, sluice gates, air entrainment, hydraulic jump, aerated water flow, air vents, La Tuque Generating Station, Isle-Maligne Generating Station. 


\section{Introduction}

Hydroelectric power is a vital source of energy for Quebec. However, many power stations were built during the first quarter of the 20th century, and almost all of them still operate with mostly the original components and equipment. In the event of a turbine-generator unit failure, it will be necessary to close the upstream intake gates as an emergency response, to stop water flow through the penstock to the unit (Fig. 1). Closing the intake gates is also necessary when a station needs an urgent rehabilitation such as turbine or air-vent replacements.

During emergency closure, water flow into the penstock is greatly reduced as the gate is lowered (Fig. 1). This could cause a dramatic air pressure differential above the reduced volume of water which should be equalised to prevent collapse. The structural integrity of the station during such a situation hinges on re-establishing a pressure equilibrium in the penstock chamber. This feat is supposedly achieved through the use of air vents extending from the outside of the station which allow a rapid influx of air to reach the penstock. How high will the safety risks be to the aging station's structural and mechanical components during emergency closure? The objectives of this paper are to develop reliable methods for estimating the pressure drop in the penstock and to validate the methods using field data.

The air vent system (Fig. 1) behind the intake gates of aging stations was designed without a sound theoretical background. Engineers used a rule of thumb or practical recommendations to determine the size of air vents, often on the basis of the maximum rate of water flow for turbinegenerator operations. This is an approximation that may be inconsistent with hydraulics principles and, to a large extent, is inaccurate for the situation of intake gate closure. Relevant hydraulic processes to consider include: the underflow of water though the gate opening, air entrainment in the penstock, air-water outflow through a turbine, and airflow through air vents.

The underflow is a bottom-bounded jet, with contracting streamlines downstream of the gate 
opening until the flow reaches the minimum depth at the vena contracta. The head-discharge relationship is of practical importance. Substantial efforts have been made to determine the coefficient of discharge (Cassan and Belaud 2011; Habibzadeh et al. 2011; Henry 1950; Lin et al. 2002; Rajaratnam and Subramanya 1967; Swamee 1992). Depending on the tailwater depth, the underflow can be submerged. Lozano et al. (2009) discussed a combination of the energy and momentum equations to analyse submerged flow. Clemmens et al. (2003) proposed an energy correction model. However, there remain unanswered questions related to energy correction (Wahl 2004). Falvey (1980, pp. 113-114) considered the formation of a submerged hydraulic jump downstream from the gate.

Kalinske and Robertson (1943) proposed an expression for the amount of air entrained by the jump, based on dimensional analysis and model studies. The Froude number is an important parameter. Air entrainment occurs in the penstock during emergency closure, presumably through both singular aeration (Chanson 2008) and interfacial aeration (Chanson 1991). The mechanism of air entrainment is not yet fully understood, in spite of earlier research efforts. Air entrainment produces an air-water mixture, with both air packets within water and water droplets surrounded by air (Chanson 2008). The problem is complicated, and simple scaling arguments can give predictions of entrainment rate over 4 orders of magnitude in the dimensionless jet speed (Lorenceau et al. 2004). Chanson (2009) raised concerns about extrapolating laboratory results to large size prototype structures using a Froude number similitude. Laboratory Reynolds numbers are typically much smaller than those in the corresponding prototype flows. This is an unresolved issue. Gualtieri and Chanson (2007) observed rapid detrainment near the jump toe and a structured air diffusion layer over longer distances. According to Chanson and Gualtieri (2008), artificial scale effects can be very problematic, giving errors in determining air entrainment in the hydraulic jump. Field data of air entrainment in water flow are very sparse. 
Several methods are available to estimate the airflow rate down an air vent. The Darcy equation is widely used to calculate the major loss of pressure due to friction in the flow. The friction factor as input to the calculation may be obtained from the Colebrook-White equation (Colebrook 1939). The two equations can be combined to yield a relationship linking the airflow rate to the conduit diameter and pressure loss per unit length. The pressure loss should include minor losses due to flow separation in bends, enlargements, and exits as part of the air vent. Crawford et al. (2007) gave an example of separation loss in bends.

Few studies of air pressure drop in penstock chambers and air demand have been carried out in the past. In a physical and numerical modelling study of the problem, Aydin (2002) ignored air entrainment. Air entrainment at the field scale cannot be ignored in pressure drop analyses. A failure to allow for air entrainment will lead to disagreement with actual test data (Borodina 1969). Jaramillo and Villegas (1988) measured air demand from a 1:25 physical model and a prototype penstock. The prototype measurements had accuracy issues because air re-entered the penstock from downstream, leading to inconclusive results. McKee et al. (1996) performed a numerical investigation of air and water flow in a penstock caused by closing the intake gate. The model domain used was simple and highly idealised, and the solutions corresponded to low Reynolds numbers. The need for an improved understanding of the pressure drop problem has motivated the present study.

\section{Study Sites}

The La Tuque Generating Station is located at $\left(47^{\circ} 26^{\prime} 39^{\prime \prime N}, 72^{\circ} 47^{\prime} 58^{\prime \prime W}\right)$ in the St. Maurice River between Chambord and Trois-Rivières in Quebec. This station was commissioned between 1940-1955, with a generating capacity of 294 megawatts. It is a run-of-river type of station, with a low head of $34.75 \mathrm{~m}$ (Fig. 1). The station has two penstock chambers (the left and the right 
chambers), with a storage volume of $836 \mathrm{~m}^{3}$. The flow of water feeding the penstock for generating electricity was controlled by two steel Stoney gates (intake gates) of rectangular shape. The full gate opening had a height of $9.30 \mathrm{~m}$ and a width of $4.57 \mathrm{~m}$. The two penstock chambers each had two air vents (only one is shown in the definition diagram in Fig. 1). The air vents had an equivalent length of $L=12.0 \mathrm{~m}$ and a diameter of $D=45.72 \mathrm{~cm}$ (Fig. 1). Parameters and conditions relevant to the problem of air-pressure drop during emergency closure are summarised in Table 1.

In a field program conducted at the La Tuque Generating Station in 2006 by Hydro-Québec, air capture hoods were mounted at the entrance of each air vent for measurements of air demand, triggered by a sudden closure of the gate (Figs. 1 and 2 ). At the $100 \%$ opening of the wicket gates around the outside of a Francis turbine's rotating runner, the closure with a synchronised group was performed by closing the intake gate to the right chamber with the intake gate to the left chamber already closed. According to field data sheets from Hydro-Québec, the gates came to a complete closure in a time period of $T=446 \mathrm{~s}$.

The 2006 field program at the station produced time series of airflow velocity $v$ at a time interval of $0.1 \mathrm{~s}$ (or $10 \mathrm{~Hz}$ ). The peak velocities were 76 and $73 \mathrm{~m} / \mathrm{s}$, respectively, at the entrances of the two air vents leading to the left chamber, and 152 and $157 \mathrm{~m} / \mathrm{s}$, respectively, at the entrances of the two air vents leading to the right chamber. Integrating these time series yielded a volume of inflowing air of $3891 \mathrm{~m}^{3}$. This is much larger than the storage volume of the two penstock chambers. Thus, the inflowing air mass must have been entrained by the turbulent flow of water leaving the penstock. Field measurements of airflow rate from the La Tuque Generating Station is available for validation of the analysis methods presented in the next section. 
Field measurements of pressure drop from the Isle-Maligne Generating Station are also available for validation of the methods. This station is located at $\left(48^{\circ} 34^{\prime} 37^{\prime \prime} \mathrm{N}, 71^{\circ} 38^{\prime} 05^{\prime \prime} \mathrm{W}\right)$ in the Saguenay-Lac-Saint-Jean region of Québec. As reported in Hydro-Québec (2013), the measurements were made in 2013 during the course of closing the station's butterfly intake-gate. Relevant parameters and conditions for the station are summarised in Table 1. For more details about the field measurements, refer to Hydro-Québec (2013).

\section{Methods}

Inflow of Water to the Penstock

Over the course of emergency closure, lowering the intake gate (Fig. 1) reduced the gate opening height $w$ (Fig. 2) with time $t$ as

[1] $\frac{w(t)}{w(0)}=1-\frac{t}{T}$

where $w(0)$ is the initial (or full) gate-opening height. The pace of closure was assumed as constant. Let $y_{1}$ denote the upstream depth of flow (Fig. 2) at a distance well upstream of the stagnation zone. This depth remained constant over the course of closure. Combining the energy and continuity equations gives a head-discharge relationship of the form (Chow, 1966, p. 508)

[2] $Q=C_{d} b w \sqrt{2 g y_{1}}$ (for free flow)

where $Q$ is the discharge of water (Figs. 1 and 2), $C_{d}$ is the dimensionless coefficient of discharge, $\mathrm{b}$ is the gate width, and $g$ is the gravity. $C_{d}$ is introduced to allow for the effects of the omitted upstream velocity-head $\left(v_{1}^{2} / 2 \mathrm{~g}\right)$, friction and streamline contraction. Note that the velocity head is much smaller than $y_{1}$. The relationship given by Eq. 2 holds under free flow condition [Fig. 2(a)]. 
Such a condition occurred only after the water level immediately downstream of the gate (Fig. 1) dropped to a certain threshold over the course of gate closure. Before then, the gate was partially or fully submerged. At the early stage of closing the gate from its fully open position, the flow underneath the gate was deeply submerged [Fig. 2(b)]. For submerged flow, $y_{1}$ in Eq. 2 should be replaced by the effective head $\left(y_{1}-y\right)$, where $y$ is the downstream depth of flow [Fig. 2(b)]. The resultant head-discharge relationship is

[3] $Q=C_{d} b w \sqrt{2 g\left(y_{1}-y\right)} \quad$ (for fully submerged flow)

In the occurrence of submerged hydraulic jump, a theoretical expression for $y$ can be derived from the momentum and continuity equations (Chow 1966, p. 60) as $y=y_{3}\left[1+2 \mathrm{~F}_{3}^{2}\left(1-y_{3} / y_{2}\right]^{1 / 2}\right.$, where $y_{2}$ is the depth of flow at the vena contracta [Fig. 2(b)], $y_{3}$ is the tailwater depth, and $\mathrm{F}_{3}$ is the Froude number evaluated as $\mathrm{F}_{3}=v_{3} /\left(g y_{3}\right)^{1 / 2}$. The first order approximation gives $y \approx y_{3}$. Here, $y_{2}$ was taken as equal to the height of gate opening.

Between Eqs. 2 and 3, the coefficient $C_{d}$ has significantly different values. Actually, the coefficient $C_{d}$ in Eq. 3 for submerged flow varies considerably, depending on two depth ratios: $y_{1} / w$ and $y_{3} / w$. The values of $C_{d}$ were determined on the basis of Henry's (1950) experimental data for the ranges of $2<y_{3} / w<8$ and $2<y_{1} / w<16$. Note that $C_{d}$ values for submerged flow approach asymptotically the corresponding $C_{d}$ value for free flow. The distinguishing condition between free and submerged flows was based on a submergence parameter (Brunner 2010, Chapter 8, pp. 8-9), defined as $s=\left(y_{3}-0.5 w\right) /\left(y_{1}-0.5 w\right)$. The flow underneath the gate was considered to be free if $s<0.67$, fully submerged if $s>0.8$, and partially submerged if $0.67 \leq s \leq$ 0.8. For partially submerged flow, the head-discharge relationship is given by (Brunner 2010, Chapter 8, pp. 8-9)

[4] $Q=C_{d} b w(5.5-5.63 s) \sqrt{2 g\left(y_{1}-y_{3}\right)} \quad$ (for partially submerged flow) 


\section{Outflow of Water from the Penstock}

The outflow of water $Q_{t}$ exiting the penstock through a turbine (Fig. 1) is expressed as a function of the gross turbine head $h$ (Gulliver and Arndt 1991, p.11.14)

$$
Q_{t}=Q_{11} h^{Z}
$$

where $Q_{11}$ is the coefficient of turbine discharge, and $Z$ is a power coefficient (Table 1 ). These coefficients are obtained by fitting a curve for a selected region of the performance hill chart that is either expected to give the most conservative results or represents a region of higher occurrence.

Over the course of closure, $Q_{t}$ decreased because $h$ dropped. The head $h$ was determined as

$$
h=h_{p}-h_{t}-\Delta p / \gamma_{0}
$$

where, $h_{p}$ is the water level in the air vent or in the penstock when the air vent becomes dry (Fig. 1); $h_{t}$ is the water level in the tailrace; $\Delta p=p_{0}-p$ is the difference between the standard atmospheric pressure $p_{\mathrm{o}}$ and the air pressure $p$ in the penstock chamber; and $\gamma_{o}$ is the specific weight of air at the standard atmospheric pressure. The water level $h_{t}$ remained constant over the course of closure.

\section{Change of Water Level in the Penstock}

The water level $h_{p}$ (Eq. 6) in the penstock dropped over the course of closure. The changing water level was determined as follows. The change in the volume of water $\Omega$ within the penstock is governed by the continuity equation

[7] $d \Omega / d t=Q-Q_{t}$

Integrating this equation over time gave a time series of $\Omega$. For given geometry of a penstock and air vents, a relationship between $h_{p}$ and $\Omega$ was established. This relationship permitted the determination of $h_{p}$ as a function of $\Omega$ 
[8] $\quad h_{p}=F(\Omega)$

Although such a function is site-specific, the idea is applicable to any site.

\section{Inflow of Air Mass to the Penstock}

As the water level in the penstock chamber dropped, the air pressure in the penstock chamber would fall below the atmospheric pressure or $p<p_{\mathrm{o}}$. This sucked air mass into the penstock from outside (Fig. 1). The inflow of air mass $m$ through the air vent is given by

$$
m=\pi(D / 2)^{2} \rho \int v d t
$$

where $\rho_{\mathrm{o}}$ is the density of air at the standard atmospheric pressure.

Estimates of the airflow velocity $v$ needed to evaluate $m$ (Eq. 9) are based on a balance between pressure head drop and airflow head losses $p_{\mathrm{o}} / \gamma_{\mathrm{o}}-p / \gamma=h_{f}+h_{m}$, where $\gamma$ is the specific weight of air in the penstock, $h_{f}$ is the major loss due to friction, and $h_{m}$ is the sum of minor losses caused by air-vent geometric features (Table 1). The Darcy-Weisbach equation gives $h_{f}=$ $f(L / D) v^{2} /(2 g)$, where $f$ is the friction factor. The value of $f$ was obtained using the ColebrookWhite equation (Colebrook 1939). The sum of minor losses is expressed as $h_{m}=k v^{2} /(2 g)$, where $k$ is the aggregated coefficient of minor losses (Table 1) due to expansion, contraction, bends and so on. Substituting the $h_{f}$ and $h_{m}$ expressions into the balance gives $v$ as

[10] $\quad v=\frac{\sqrt{2 g\left(p_{\circ} / \gamma_{\circ}-p / \gamma\right)}}{\sqrt{f L / D+k}}$

This equation for estimating $v$ has excluded the effect of change in elevation head, which is insignificantly small in comparison to the pressure head.

Outflow of Air Mass from the Penstock 
The underflow of water (Fig. 2) was a high-speed jet, capable to entrain air from above the water surface in the penstock. As a result, a mixture of water and air bubbles flowed along the penstock and through the turbine into the tailrace (Fig. 1). Let $q_{t}$ denote the outflow of air from the penstock. The air outflow is given by

[11] $q_{t}=\beta Q_{t}$

where $\beta$ is a ratio parameter. This parameter was used to achieve calibration of air entrainment. The formulation of $\beta$ is discussed below.

Laboratory observations (Aydin 2002) indicated the presence of submerged and free-surface hydraulic jumps in penstocks during the course of gate closure. Assume that air entrainment in the penstock is caused by similar turbulence conditions as in a hydraulic jump. USACE (1977, Hydraulic Design Chart 050-1) recommended that $\beta=0.03\left(\mathrm{~F}_{2}-1\right)^{1.06}$, where $\mathrm{F}_{2}$ is the Froude number evaluated at the vena contracta or $\mathrm{F}_{2}=Q /\left(b g^{1 / 2} y_{2}^{3 / 2}\right)$. The $\beta$ expression was modified as

$$
\beta=0.03 c c_{j}\left(\mathrm{~F}_{2}-1\right)^{1.06}
$$

The coefficient $c$ allowed for the effect of penstock geometric characteristics downstream of possible hydraulic jump. Its values were adjusted to achieve the best comparison between calculated and observed air pressure drops. The coefficient $c_{j}$ ranged from zero to one. It remained to be zero until the water level dropped to the air vent junction (Fig. 1), meaning no air entrainment when water still occupied the air vent. Subsequently, $c_{j}$ increased linearly from zero, and reached one when the water level dropped to the level at which $\mathrm{F}_{2}$ was the maximum. This requires back calculations. The $c_{j}$ value remained the same until the water level reached the gate tip (Fig. 1).

When the water level downstream of the gate was lower than the tip, air entrainment was considered to be due to a water jet discharging into air. This approximation assumes the absence of a lower boundary to the jet, which is acceptable when the penstock bottom inclines at an angle 
to a nearly horizontal sill (Fig. 1). Calculations of air entrainment follow the procedures of Chanson (2008). For details, refer to Chanson (2008).

With $q_{t}$ given in Eq. 11, the air mass contained in the outflow of an air-water mixture is

$$
m_{t}=\int \rho \beta Q_{t} d t
$$

where $\rho$ is the density of air in the penstock. Its value was interpolated from charts according to air temperature and pressure. Between Eqs. 9 and 13, the change in air mass in the penstock was obtained as $\Delta m=m-m_{t}$. This can be converted to change in air volume as $\Delta V=\Delta m / \rho$.

\section{Air Pressure in the Penstock}

A drop in water level in the penstock chambers (Fig. 1) means an expansion in the volume of air $V$ above the water surface, and hence a drop in air pressure $p$. Boyle's Law gives $p(t+\Delta t) V(t+$ $\Delta t)=p(t) V(t)$, where $\Delta t$ is a small time interval. If the volume $V$ expands by $\Delta V$, the pressure $p$ will drop to $p(t+\Delta t)=p(t) /[1+\Delta V / V(t)]$. This is true before considering air mass inflow (Eq. 9) to and outflow (Eq. 13) from the penstock. The former causes an increase in $p$, whereas the latter causes a decrease. This leads to

$$
p(t+\Delta t)=p(t) \frac{V+\Delta m / \rho}{V+\Delta V}
$$

The terms on the right hand side of this equation were evaluated at the current time $t$.

\section{Computational Procedures}

Because the calculations of water inflow (Eq. 3 or 4) and outflow (Eq. 5) require the water level $h_{p}$ (Eqs. 7 and 8 ) as input, and vice versa, it is necessary to use iterative procedures to determine the three unknowns as well as the unknown air pressure (Eq. 14) in the penstock. Successive 
estimates of unknown variables involved were obtained until air inflow to the penstock was in balance with the water level.

The main steps of calculations are outlined below:

1) Assign a value to water level $h_{p}$, and determine the corresponding volume of water $\Omega$.

2) Calculate the gate opening (Eq. 1).

3) Determine the head $h$ (Eq. 6) and outflow $Q_{t}$ (Eq. 5).

4) Take the water level $h_{p}$ relative to the sill [Fig. 1(b)] as the depth of flow $y_{3}$ [Fig. 2(b)]

5) Calculate the inflow of water $Q$ (Eq. 2, 3 or 4).

6) Calculate the change in $\Omega$ (Eq. 7), give the change in air volume $\Delta V$ the same magnitude as the change in $\Omega$ but an opposite sign, and update $h_{p}$ (Eq. 8).

7) Determine air velocity $v$ (Eq. 10), and the inflow of air mass $m$ (Eq. 9).

8) Determine parameter $\beta$ (Eq. 12), and the outflow of air mass $m_{t}$ (Eq. 13).

9) Find the change in air mass $\left(\Delta m=m-m_{t}\right)$.

10) Update the air pressure (Eq. 14).

The above-mentioned steps are repeated for a desired period of time. At each time step, the iterative procedures produce solutions that closely satisfy the energy and continuity principles.

\section{Results}

Relationship between Water Volume and Water Level in the Penstock

During the course of gate closure, the water level $h_{p}$ (Fig. 1) dropped for the following reason. The blades quickly entered the upstream part of the penstock and increased the blockage. This caused an increase in head loss, which manifested itself in the form of a lowering water level in the air vent or penstock. As $h_{p}$ continued to drop, the air vent became completely dry. The water 
level dropped to the junction between the air vent and the penstock. The air pressure $p$ in the penstock chamber began to drop (or $\Delta p>0$ ). This resulted in a decreases in the head $h$ (Eq. 6).

The relationship (Eq. 8) between water volume $\Omega$ in the penstock and $h_{p}$ is plotted as the dashed curve in Fig. 3 for the La Tuque Generating Station. This curve was obtained by casting Eq. 8 from the general to the specific form, considering the geometric features of the penstock and the air vents. The features included the actual cross-sectional shape, dimensions, and inclination angle. Along the curve, the point of a sudden increase in slope represented the connecting section between the penstock chamber and the air vent system. The water volume corresponding to the sudden change in slope was the design storage capacity of the penstock. The storage capacity of the La Tuque Generating Station was close to $1400 \mathrm{~m}^{3}$. This curve provided necessary geometric information for the calculation of airflow in the air vents, air demand due to void spaces in the penstock, and air-pressure drop.

\section{Discharge of Water through the Intake-Gate Opening}

A time series of water discharge through the intake gate opening, calculated using Eqs. 2, 3 or 4, and a time series of water velocity at the gate section are shown in Fig. 4. In the first half of the time period of gate closure or $t<T / 2$, the discharge of water [Fig. 4(b), the dashed curve] dropped at a slower rate than the gate opening height (Eq. 1). This means that the crosssectionally averaged water velocity [Fig. 4(a)] increased with time or the water jet intensified. For example, before gate closure, the jet velocity at the gate section was $5.18 \mathrm{~m} / \mathrm{s}$, as determined from an initial discharge of $220 \mathrm{~m}^{3} / \mathrm{s}$, a gate width of $4.57 \mathrm{~m}$ and a gate opening height of $9.30 \mathrm{~m}$ (Table 1). At half-time of the closure period, the jet velocity at the gate section increased to 8.28 $\mathrm{m} / \mathrm{s}$, although the discharge of water through the gate opening decreased from its initial value. The intensification of water jet enhanced air entrainment in the penstock chamber. For the La 
Tuque Generating Station, the volumetric rate of air entrainment was at its maximum when the Froude number reached 4.71 .

\section{Outflow of Water to the Tailrace}

In Fig. 4(b), a time series of water outflow (the solid curve) through the turbine is plotted. Calculations of the outflow are based on Eq. 5, in which the coefficients $Q_{11}$ and $Z$ (Table 1) are fixed for a given turbine machine operating at a fixed specific speed (Gulliver and Arndt 1991, p. 4.12). The initial value of outflow was equal to that of the discharge through the intake gate opening as the gate was fully open. The inflow [Fig. 4(b), the dashed curve] overlapped the outflow [Fig. 4(b), the solid curve] until the gate opening reduced to about one-thirds of the initial gate opening. The time period of overlap was about two thirds of the time period $(T)$ it took to close the gate. This finding has implications to proper emergency closure manoeuvres. Over the last one third of the time period $T$, the solid curve is plotted to the right of the dashed curve, meaning that the outflow exceeded the inflow.

This moment marks the beginning of significant air demand. Air demand due to void space filling and that due to entrainment by water flow remained null until the last third of the time period. Air entrainment by flowing water was not allowed in the calculation until the water level descended in the air vent and incoming turbulent flow to the chamber became directly in contact with air. This was controlled through the coefficient $c_{j}$ in Eq. 12, which was set to one when air reached the penstock chamber and to zero before that time. This treatment is realistic.

The condition of overlap is greatly dependent on the water level - water volume relationship of the penstock (Fig. 3). The particular shape created between the time series of the inflow and outflow was due to a routing effect. For instance, the separation between inflow and outflow data series occurred when the water level inside the air vent reached the penstock chamber. There was 
a clear relationship between the vertical distance between these two curves, and the data series of the air demand required to replace the water volume as it decreased.

\section{Relationship of Pressure Drop to Airflow through the Air Vents}

For a given penstock, the relationship between the volume of water and the water level is most likely to be specific. This is because the penstock has particular geometric features. Similarly, a given air vent system is most likely to have particular geometric features, and specific values for the coefficients of major and minor head losses (Table 1). Therefore, it would be necessary and convenient to establish the relationship between air pressure drop in the penstock chamber and the volumetric rate of airflow through the air vent. The relationship for the La Tuque Generating Station is graphically shown in Fig. 5.

On the horizontal axis of this figure, the air pressure drop is the standard atmospheric pressure $\left(p_{\mathrm{o}}=101.325 \mathrm{kPa}\right)$ outside the air vents minus the air pressure in the penstock chamber. This difference in pressure will cause airflow through the air vent system at a velocity given in Eq. 10, written in terms of pressure head drop $\Delta p$. On the vertical axis, the volumetric rate of airflow is the airflow velocity times the cross sectional area (Table 1) of the air vent system.

One way to use the pressure drop - airflow relationship is explained through an example given below: Suppose that the penstock-chamber air pressure $p$ is below $p_{\mathrm{o}}$ at $84.325 \mathrm{kPa}$. The pressure difference will be $16.0 \mathrm{kPa}$ (Fig. 5). This will cause air inflow to the chamber at a volumetric rate of about $68 \mathrm{~m}^{3} / \mathrm{s}$.

Another way to use the pressure drop - airflow relationship is to find the expected pressure drop in the penstock chamber from measurements of airflow through the air vents. At the La Tuque Generating Station (Fig. 5), the static pressure gauge installed in the air vents for air pressure measurements got submerged by water in the 2006 field program of Hydro-Québce. As 
a result, the air pressure had to be computed from measurements of airflow velocity and estimated head losses of airflow through the air vents. Note that air velocities were measured using a high-velocity air capture hood. To the best of our knowledge, this represents the first time to obtain pressure drop that fits such a curve (Fig. 5) in the manner described above.

\section{Air Demand and Pressure Drop}

In Fig. 6(a), a time series of calculated airflow rate (the dashed curve) for the La Tuque Generating Station is compared with measurements (the solid curve). Along the two curves, the peak value of calculated flow rates is in good agreement with the measured peak value. The calculation appeared to give a total air volume (the area under the dashed curve) passing through the air vents, which was too large compared to the measurements (the area under the solid curve). This was mainly because the analysis methods developed was calibrated to capture the peak (or maximum) pressure drop behind the intake gate. The maximum pressure drop is more critical than the duration of off-peak pressure drops as far as the resultant force on the gate is concerned.

In Fig. 6(a), a dissection of the calculated total air entrainment shows void replacement air demand and corrected (with $c_{j}=1.61$ in Eq. 12) air entrainment demand. These curves reveal the relative importance of the physical processes involved in the problem of pressure drop in the penstock chamber. For the La Tuque Generating Station, the calculated maximum drop of air pressure inside the chamber was around $36 \mathrm{kPa}$.

\section{Discussion}

The graphic solution (Fig. 3) to Eq. 8 has a number of advantages: The approach ensures relevance to the penstock under investigation, because of the use of the actual geometry of the 
penstock without any scale reduction. The approach is valid for penstocks of general cross section, representing an improvement from earlier studies, which typically assumed constant penstock geometry. More importantly, the approach avoids the issue of a lack of Reynolds number similarity. For example, Aydin (2002) analysed a hydraulic model on 1:40 scale, which met the requirement of Froude number similarity, but not Reynolds number similarity (the Reynolds number of the hydraulic model being much lower than that of the prototype). Yet, the author formulated the local loss coefficients in the energy balance equations as a function of the Reynolds number. This can be problematic. Great concerns have been raised in the literature about scaling up using a Froude similitude (Chanson 2009). The most problematic formulation is that the flow in the penstock is assumed to be laminar, as in McKee et al. (1996).

The time series plotted in Fig. 4(b) showed a roughly linear decrease in the calculated discharge of water through the gate opening at the early stage of emergency closure. One expects a more gradual and non-linear rather than a linear decrease at the early stage. The linear trend is perhaps due to an over emphasis of the effect of the gate opening height on the discharge (the factor $w$ in Eqs. 2, 3 and 4) at the early stage of gate closure. Aydin (2002) distinguished between downstream controlled flow and gate controlled flow, and considered that the gate opening had no control on the discharge up to a certain gate closure, and it controlled the discharge only when the gate closure was enough. It would be constructive to test whether or not the consideration improves the results at the field scale.

Theoretically, analyses of the problem of air pressure drop in a penstock should consider not only the air mass that flows down the air vents to fill the void in the penstock but also the air mass in the penstock chamber that is entrained by turbulent water motions and flows out of the penstock. As evidenced by the field measurements discussed in the "Study Site" section of this paper, the process of air entrainment and discharge is important, but has been ignored in some 
existing modelling studies (Aydin 2002; McKee et al. 1996). Their studies used the concept of streamlines, making it difficult to incorporate air entrainment and discharge in the formulation of the problem. The key to success in this paper lies in quantifying both the void filling and air entrainment processes.

In reality, air vents rarely consist of simple pipes or wells open to the outside and connected to the penstock. They typically include air dampers, elbows, expansions, contractions, complex manifolds, ladders, covers, protruding inlets, and steel grates. They often utilise an inspection tunnel to reach the outside. The analysis methods developed in this paper allow the flexibility to include the influences of air-vent system components like those mentioned above through a lumped parameter (Table 1). The methods can easily be adopted and used to estimate air pressure drop in other penstocks during gate closure.

As an example to test the methods' robustness, estimates of pressure drop for the Isle Maligne Generating Station are compared with available field measurements (Hydro-Québec 2013) in Fig. 6(b). The two time series had similar shape: One is the measured pressure drop (solid curve), and the other is the calculated pressure drop (dashed curve). The measurements contained significant fluctuations until the pressure drop reached the maximum, and had an offset value of about $1.5 \%$ of the atmospheric pressure. Air pressure drop inside the penstock chamber was measured to peak at $24.9 \mathrm{kPa}$ at about $t=240 \mathrm{~s}$ after the beginning of the gate closure, whereas the calculated peak pressure drop was about $23.0 \mathrm{kPa}$ at a time lag of about 12 s. The calculated discharge of water through the gate opening at time $t=0$ was $121.4 \mathrm{~m}^{3} / \mathrm{s}$, compared with a measured value of $126.2 \mathrm{~m}^{3} / \mathrm{s}$.

It is understood that the pressure field in a penstock contains inherent fluctuations due to the turbulent and chaotic nature of air-water flows. Such fluctuations and pressure offset values create difficulties in making field measurements of air pressure and other related parameters 
from a penstock. Moreover, it is very expensive to make field measurements. The analysis methods presented in this paper are deterministic, and therefore are not able to capture any fluctuations in the pressure field.

Note that a great vacuum within a penstock may cause the intake gates themselves to break, the separation of concrete patches within the penstock which could destroy the turbine, or even the collapse of the generator's floor located above the penstock. Broken gates during emergency closure would be particularly problematic with the wicket gates being locked in fully or partially open position. It would then be very difficult, if not impossible, to cut the water flow through the turbine. It is important to gain accurate data of pressure distribution associated with this rare but important event and to understand any sensitive elements that could lead to a catastrophe.

In Quebec, emergency closures have never been tested before on prototypes for some specific reasons: it is difficult to monitor the conditions, and outcomes are unknown; there has never been a manifestation of desire before today to know if a penstock could withstand or not an emergency closure; every owner relies on the accuracy of the original design, not wanting to take the chance of testing it. This paper has contributed to filling the knowledge gaps between quantitative and qualitative methodologies for application to estimates of air pressure drop in penstocks.

\section{Conclusions}

In many cases, hydroelectric generating stations built in as early as the early 20 century are still operating with mostly the original components and equipment. Often, the ventilation system intended for a supply of air to the penstock chamber of aging stations, to prevent collapse, was designed without a sound theoretical background. It is very likely that such aging stations will need urgent rehabilitation. This requires to close the upstream intake gates of the station in 
question, in order to stop water flow through its penstock (Fig. 1). An urgent closure of the intake gates is also required in the event of power trip and wicket-gate blockage. Thus, it is important to be able to predict air pressure drop in the penstock chamber during the course of gate closure, because of the safety risks posed to the station's structures and facilities.

This paper has contributed to an improved understanding of the engineering problem of air pressure drop in a penstock during the course of gate closure. The idea to establish a relationship between water-volume and water-level for the penstock in question (Fig. 3) greatly enhances relevance to the problem. This is because the relationship is based on the actual geometric configurations of the real-world penstock at field scales, being superior to reduced-scale laboratory models and prototype models with highly simplified geometry. The use of field-scale input to calculations reduces uncertainties in estimates of air entrainment, which is an important process in the problem of air pressure drop. Although the relation reported in this paper is station-specific, the idea can readily be applied to any stations.

To the best of our knowledge, for the first time, this paper has formulated the problem of penstock pressure in a way that is consistent with time-dependent energy, momentum and continuity principles. The formulation has considered time-dependent underflow of water though the changing gate opening, air entrainment in the penstock, outflow of an air-water mixture through a turbine, and airflow through air vents. These considerations represent a significant advancement from the use of practical recommendations or purely empirical formulae, which, to a large extent, are inaccurate for the situation of intake gate closure.

The analysis methods presented in this paper give reliable estimates of air demand and pressure drop in the penstocks at the La Tuque and the Isle Maligne Generating Stations during the course of closing the intake gates. There is an excellent agreement between the calculated air pressure and measured values, the calculated peak value being within $95 \%$ of the measurement. 
Such agreement demonstrates the robustness of the calculation procedures. The accuracy can further be improved by accounting for the peculiarity of the penstock's geometric features.

Air entrainment by high-velocity flowing water is an important cause of air pressure drop in emergency closure and therefore must be considered in order to accurately simulate the process. Unfortunately, air entrainment has been ignored in some prior studies of the problem of air pressure drop in a penstock.

Air entrainment in the outflow can be modelled using hydraulic-jump entrainment equations. This paper has demonstrated that a coefficient of 1.61 is well suited for the estimation of entrained air demand in a penstock as long as it has similar geometric and operating parameters as the La Tuque and Isle Maligne penstocks. Future applications of the analysis methods to other stations should pay close attention to values assigned to this coefficient.

In emergency closure of intake gates, the amount of water discharge underneath the gate does not proportionally reduce to the percentage of instantaneous gate opening. The velocities of the water jet intensify in the first half of the time period it takes to close the gate, which would produce significant impacts on the penstock structures.

Air demand appears to commence when the outflow through the turbine to the tailrace in question exceeds the inflow underneath the intake gate. This occurs mainly in the last one third of the time period of emergency closure.

The values of pressure drop calculated for the Isle-Maligne and the La Tuque Generating Stations are below one third of the standard atmospheric pressure. It is cautioned that the calculations have made no attempt to account for air pressure fluctuations inherently occurring in turbulent and chaotic air-water flows in the penstocks in emergency closure. Given that the fluctuations can be very significant, one should use field measurements and results from mathematical analysis in a complementary manner. 


\section{Acknowledgement}

Financial support from the Natural Sciences and Engineering Research Council of Canada through Discovery Grants held by Dr. Li is acknowledged.

\section{References}

Aydin, I. 2002. Air demand behind high head gates during emergency closure. Journal of Hydraulic Research 40(1): 83-93. doi:10.1080/00221680209499876.

Borodina, L.K. 1969. Aeration behind low-level gates. Hydrotechnical Construction 3(9): 826834.

Brunner, G.W. 2010. HEC-RAS, River analysis system hydraulic reference manual. US Army Corps of Engineers, Hydrologic Engineering Center, Davis, CA.

Cassan, L., and Belaud, G. 2011. Experimental and numerical investigation of flow under sluice gates. Journal of Hydraulic Engineering-ASCE 138(4): 367-373. doi: 10.1061/(ASCE)HY.1943-7900.0000514.

Chanson, H. 1991. Aeration of a free jet above a spillway. Journal of Hydraulic Research 29(5): 655-667. doi:10.1080/00221689109498982.

Chanson, H. 2008. Advective diffusion of air bubbles in turbulent water flows. In Fluid mechanics of environmental interfaces. Edited by C. Gualtieri and D.T. Mihailovic. Taylor \& Francis, Leiden, the Netherlands. pp. 163-196.

Chanson, H. 2009. Turbulent air-water flows in hydraulic structures: dynamic similarity and scale effects. Environmental Fluid Mechanics 9(2): 125-142. doi:10.1007/s10652-008-90783. 
Chanson, H., and Gualtieri, C. 2008. Similitude and scale effects of air entrainment in hydraulic jumps. Journal of Hydraulic Research 46(1): 35-44. doi:10.1080/00221686.2008.9521841.

Chow, V.T. 1959. Open-channel hydraulics. McGraw Hill, Caldwell, N.J.

Clemmens, A.J., Strelkoff, T.S., and Replogle, J.A. 2003. Calibration of submerged radial gates. Journal of Hydraulic Engineering-ASCE 129(9): 680-687. doi:10.1061/(ASCE)07339429(2003)129:9(680).

Colebrook, C.F. 1939. Turbulent flow in pipes, with particular reference to the transition region between the smooth and rough pipe laws. Journal of the Institution of Civil Engineers 11(4): 133-156. doi:10.1680/ijoti.1939.13150.

Crawford, N.M., Cunningham, G., and Spence, S.W.T. 2007. An experimental investigation into the pressure drop for turbulent flow in 90 elbow bends. Proceedings of the Institution of Mechanical Engineers, Part E: Journal of Process Mechanical Engineering 221(2): 77-88. doi:10.1243/0954408JPME84.

Falvey, H.T. 1968. Air vent computations, Morrow Point Dam, Colorado River storage project. Report HYD No. 584, US Department of the Interior, Bureau of Reclamation, Office of Chief Engineer, Denver, CO.

Falvey, H.T. 1980. Air-water flow in hydraulic structures. Engineering Monograph No. 41, Water and Power Resources Services, Engineering and Research Center, Denver, CO.

Gualtieri, C., and Chanson, H. 2007. Experimental analysis of Froude number effect on air entrainment in the hydraulic jump. Environmental Fluid Mechanics 7(3): 217-238. doi:10.1007/s10652-006-9016-1.

Gulliver, J.S., and Arndt, R.E.A. 1991. Hydropower engineering handbook. McGraw-Hill, New York. 
Habibzadeh, A., Vatankhah, A.R., and Rajaratnam, N. 2011. Role of energy loss on discharge characteristics of sluice gates. Journal of Hydraulic Engineering-ASCE 137(9): 1079-1084. doi:10.1061/(ASCE)HY.1943-7900.0000406.

Henry, H.R., 1950, Discussion on 'Diffusion of submerged jets', by M.L. Albertson, Y.B. Dai, R.A. Jensen, and H. Rouse: Transactions American Society of Civil Engineers 115: 687694.

Hydro-Québec. 2013. Centrale Isle Magligne Groupe No 3 essais de rupture de débit par la vanne papillon. Hydro-Québec Expertise de Centrales, Essais Spéciaux de Production. Rapport ES-2013-2019. Octobre 30, 2013.

Jaramillo, C.A., and Villegas, A.M. 1988. Air demand of high head sluice gates. In Modelprototype correction of hydraulic structures. Proceedings of the International Symposium, Colorado Springs, CO, 9-11 August 1988. pp. 95-101.

Kalinske, A.A., and Robertson, J.M. 1943. Entrainment of air in flowing water: A symposium: Closed conduit flow. Transactions of the American Society of Civil Engineers 108(1): 1435 $-1447$.

Lin, C.H., Yen, J.F., and Tsai, C.T. 2002. Influence of sluice gate contraction coefficient on distinguishing condition. Journal of Irrigation and Drainage Engineering-ASCE 128(4): 249-252. doi:10.1061/(ASCE)0733-9437(2002)128:4(249).

Lorenceau, É., Quéré, D., and Eggers, J. 2004. Air entrainment by a viscous jet plunging into a bath. Physical Review Letters 93(25): 254-501. doi:10.1103/PhysRevLett.93.254501.

Lozano, D., Mateos, L., Merkley, G.P., and Clemmens, A.J. 2009. Field calibration of submerged sluice gates in irrigation canals. Journal of Irrigation and Drainage EngineeringASCE 135(6): 763 -772. doi:10.1061/(ASCE)IR.1943-4774.0000085. 
McKee, S., Sneyd, A.D., and Tomé, M.F. 1996. Time-dependent flow in a penstock during headgate closure. Applied Mathematical Modelling 20(8): 614-623. doi:10.1016/0307904X(96)00009-1.

Rajaratnam, N., and Subramanya, K. 1967. Flow immediately below submerged sluice gate. Journal of the Hydraulics Division-ASCE 93(4): 57-77.

Swamee, P.K. 1992. Sluice-gate discharge equations. Journal of Irrigation and Drainage Engineering-ASCE 118(1): 56-60. doi:10.1061/(ASCE)0733-9437(1992)118:1(56).

USACE 1977. Hydraulic design criteria: Volume 1. U.S. Army Corps of Engineers, Washington, D.C.

Wahl, T.L., 2004. Issues and problems with calibration of canal gates. In Critical transitions in water and environmental resources management, Salt Lake City, Utah, 27 June-1 July 2004. American Society of Civil Engineers, New York, pp. 1-9.

\section{List of Symbols}

$b \quad$ flow width at the intake gate section (m);

$C_{d} \quad$ coefficient of water discharge through the intake gate opening;

$c, c_{j} \quad$ coefficients;

$D \quad$ equivalent diameter of the air vents (m);

$\mathrm{F}_{2} \quad$ Froude number evaluated at the vena contracta;

$\mathrm{F}_{3} \quad$ Froude number evaluated at the $y_{3}$ cross section;

$f \quad$ friction factor;

$g \quad \operatorname{gravity}\left(\mathrm{m} / \mathrm{s}^{2}\right)$;

$h \quad$ turbine head $(\mathrm{m})$;

$h_{f} \quad$ major head loss (m);

$h_{m} \quad$ sum of minor head losses (m);

$h_{p} \quad$ water level in the penstock above a reference datum (m);

$h_{t} \quad$ water level in the tailrace above a reference datum (m); 
$k \quad$ coefficient for minor losses of pressure;

$L \quad$ equivalent length of the air vents $(m)$;

$m \quad$ mass of air flowing into the penstock chamber $(\mathrm{kg})$;

$m_{t} \quad$ mass of air flowing out of the penstock $(\mathrm{kg})$;

$p \quad$ air pressure above the water surface in the penstock chamber $(\mathrm{Pa})$;

$p_{\mathrm{o}} \quad$ standard atmospheric pressure $(\mathrm{Pa})$;

$Q \quad$ discharge of water through the intake gate opening $\left(\mathrm{m}^{3} / \mathrm{s}\right)$;

$Q_{t} \quad$ discharge of water through the turbine $\left(\mathrm{m}^{3} / \mathrm{s}\right)$;

$Q_{11} \quad$ turbine flow parameter;

$q_{t} \quad$ discharge of air through the turbine $\left(\mathrm{m}^{3} / \mathrm{s}\right)$;

$s \quad$ submergence ratio;

$T \quad$ duration of gate closure (s);

$t \quad$ time (s);

$V \quad$ volume of air above the water surface in the penstock chamber $\left(\mathrm{m}^{3}\right)$

$y \quad$ depth of water immediately downstream of the intake gate (m);

$v_{1} \quad$ velocity of water flow in the upstream reservoir $(\mathrm{m} / \mathrm{s})$;

$v_{3} \quad$ water velocity at the $y_{3}$ cross section $(\mathrm{m} / \mathrm{s})$;

$w \quad$ intake-gate opening height $(\mathrm{m})$;

$y_{1} \quad$ depth of water flow in the upstream reservoir, relative to the sill (m);

$y_{2} \quad$ depth of water flow at the vena contracta, relative to the sill (m);

$y_{3} \quad$ downstream depth of water flow in the penstock, relative to the sill (m);

$Z \quad$ turbine flow power coefficient;

$\beta \quad$ air entrainment coefficient;

$\gamma \quad$ specific weight of air in the penstock chamber $\left(\mathrm{N} / \mathrm{m}^{3}\right)$;

$\gamma_{0} \quad$ specific weight of air at the standard atmospheric pressure $\left(\mathrm{N} / \mathrm{m}^{3}\right)$;

$\Delta t \quad$ time step (s);

$\rho \quad$ density of air in the penstock chamber $\left(\mathrm{kg} / \mathrm{m}^{3}\right)$;

$\rho_{\mathrm{o}} \quad$ density of air at the standard atmospheric pressure $\left(\mathrm{kg} / \mathrm{m}^{3}\right)$;

$\Omega \quad$ volume of water in the penstock $\left(\mathrm{m}^{3}\right)$; 


\section{Tables}

Table 1. Control and geometric parameters for the La Tuque and Isle-Maligne Generating Stations. The listed characteristic surface roughness heights of the penstocks are within the range of $0.46-3 \mathrm{~mm}$ for concrete (Chow 1959, p. 196).

\begin{tabular}{lcc}
\hline Parameter & La Tuque & Isle-Maligne \\
\hline Equivalent diameter of air vent $D(\mathrm{~m})$ & 0.46 & 0.84 \\
Length of air vent $L(\mathrm{~m})$ & 12.0 & 14.0 \\
Quantity of air vents per group & 4 & 1 \\
Full gate-opening height $w(0)(\mathrm{m})$ & 9.30 & 6.78 \\
Penstock free width at the intake gate section $b(\mathrm{~m})$ & 4.57 & 4.72 \\
Number of gate per unit & 2 & 2 \\
Characteristic surface roughness height $k_{s}(\mathrm{~mm})$ & 0.5 & 2.2 \\
Density of air at the atmospheric pressure $\rho_{\mathrm{o}}\left(\mathrm{kg} / \mathrm{m}^{3}\right)$ & \multicolumn{2}{c}{1.2041} \\
Specific weight of air at the atmospheric pressure $\gamma_{\mathrm{o}}\left(\mathrm{N} / \mathrm{m}^{3}\right)$ & \multicolumn{2}{c}{14.223} \\
Standard atmospheric pressure $p_{\mathrm{o}}(\mathrm{kPa})$ & \multicolumn{2}{c}{101.325} \\
Gravity $g\left(\mathrm{~m} / \mathrm{s}^{2}\right)$ & 0.81 \\
Sum of the coefficients of minor head losses in air vents $k$ & 446 & 0.8 \\
Time period of emergency gate closure $T(\mathrm{~s})$ & 1 & 0.07 \\
Time interval for integration $\Delta t(\mathrm{~s})$ & 20.12 & 18.60 \\
Upstream depth of water $y_{1}(\mathrm{~m})$ & 152.05 & 101.54 \\
Water level $($ above mean sea level) of the upstream reservoir $(\mathrm{m})$ & 117.97 & 67.94 \\
Water level (above mean sea level) downstream of the turbine $(\mathrm{m})$ & $40 / 0.5$ & $46.7 / 0.33$ \\
Turbine flow coefficients $\left(\right.$ the ratio $\left.Q_{11} / \mathrm{Z}\right)$ & \multicolumn{2}{c}{} \\
\hline
\end{tabular}




\section{Figure Captions}

Figure 1. Definition sketch of a vertical cross section of a hydroelectric generating station, showing an intake gate, a penstock, a turbine unit, and a tailrace.

Figure 2. Definition diagram of a vertical sluice gate: (a) free flow; (b) submerged flow.

Figure 3. The volume of water versus the water level in the penstock of the La Tuque Generating Station. The water level is in reference to a historic mean sea level.

Figure 4. Time series of calculated water velocity (panel a) at the gate opening section (Fig. 1) and calculated discharge of water (panel b), during the course of gate closure. In panel (b), the dashed and solid curves are, respectively, the discharges underneath the gate to the penstock and through the turbine to the tailrace (Fig. 1). The water velocity had an initial value of $5.176 \mathrm{~m} / \mathrm{s}$ at time $t=0$, and dropped to zero at the ending time of gate closure. The two discharges had an initial value of $220 \mathrm{~m}^{3} / \mathrm{s}$, and overlapped up to $t \approx 290 \mathrm{~s}$.

Figure 5. Relationship between air-pressure drop in the penstock and airflow rate through the air vents.

Figure 6. Comparisons of time series of airflow rate (or air demand) between measurements and calculations for the La Tuque Generating Station (panel a), and time series of air pressure drop between measurements and calculations for the Isle-Maligne Generating Station (panel b). In panel (a), the volumetric airflow rates due to air entrainment and void filling correspond to the standard atmospheric pressure. The sampling frequency of the airflow-rate and pressure-drop measurements was $10 \mathrm{~Hz}$. 


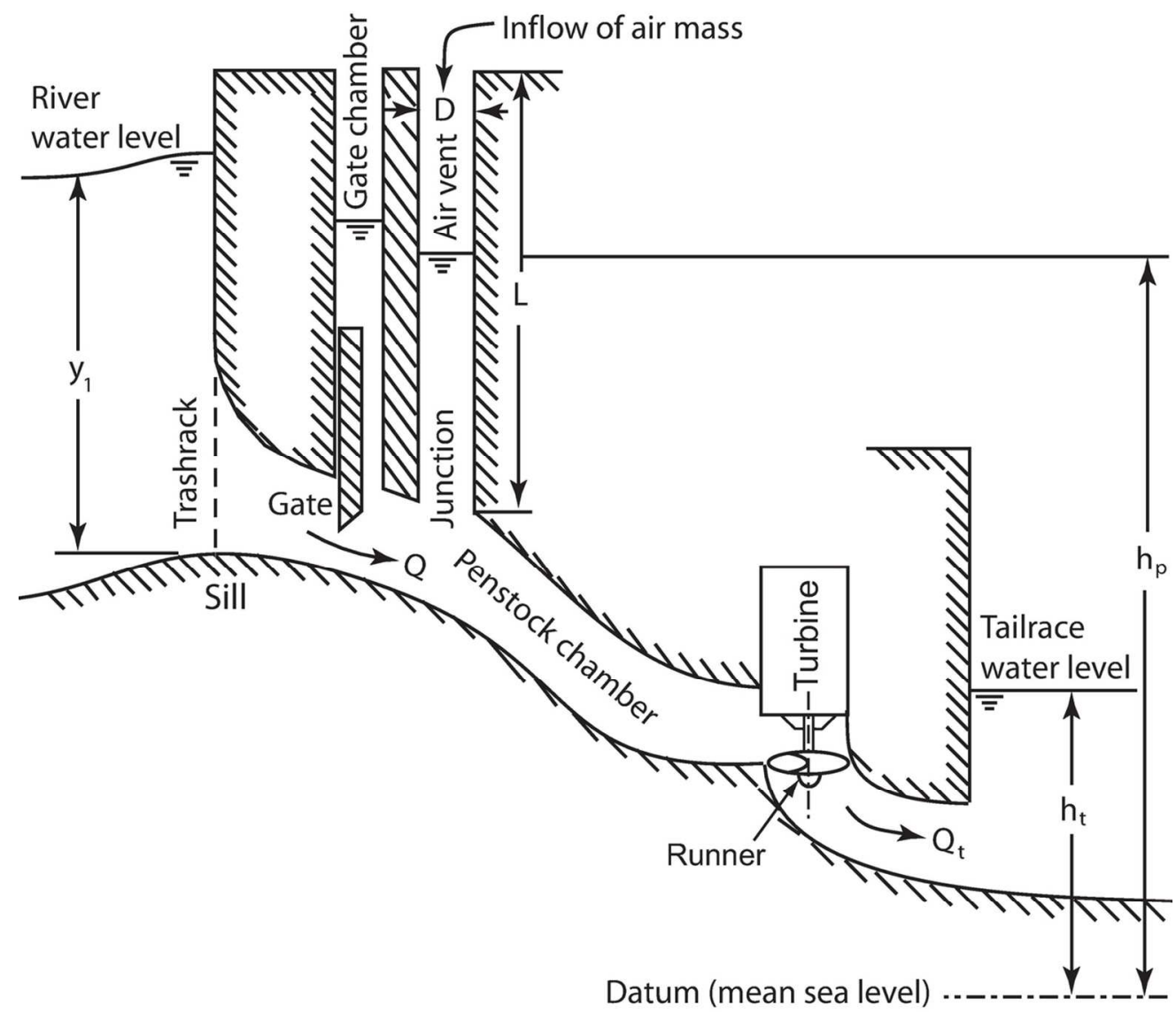

Figure 1. Definition sketch of a vertical cross section of a hydroelectric generating station, showing an intake gate, a penstock, a turbine unit, and a tailrace.

$116 \times 101 \mathrm{~mm}(300 \times 300$ DPI $)$ 

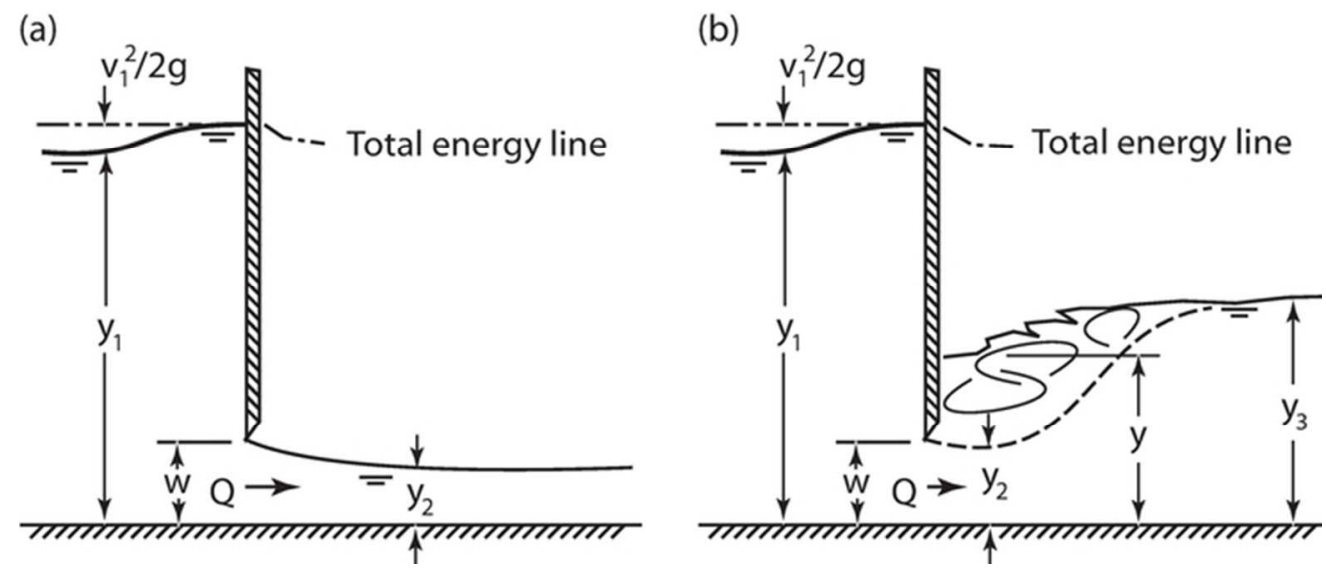

Figure 2. Definition diagram of a vertical sluice gate: (a) free flow; (b) submerged flow. $61 \times 26 \mathrm{~mm}(300 \times 300 \mathrm{DPI})$ 


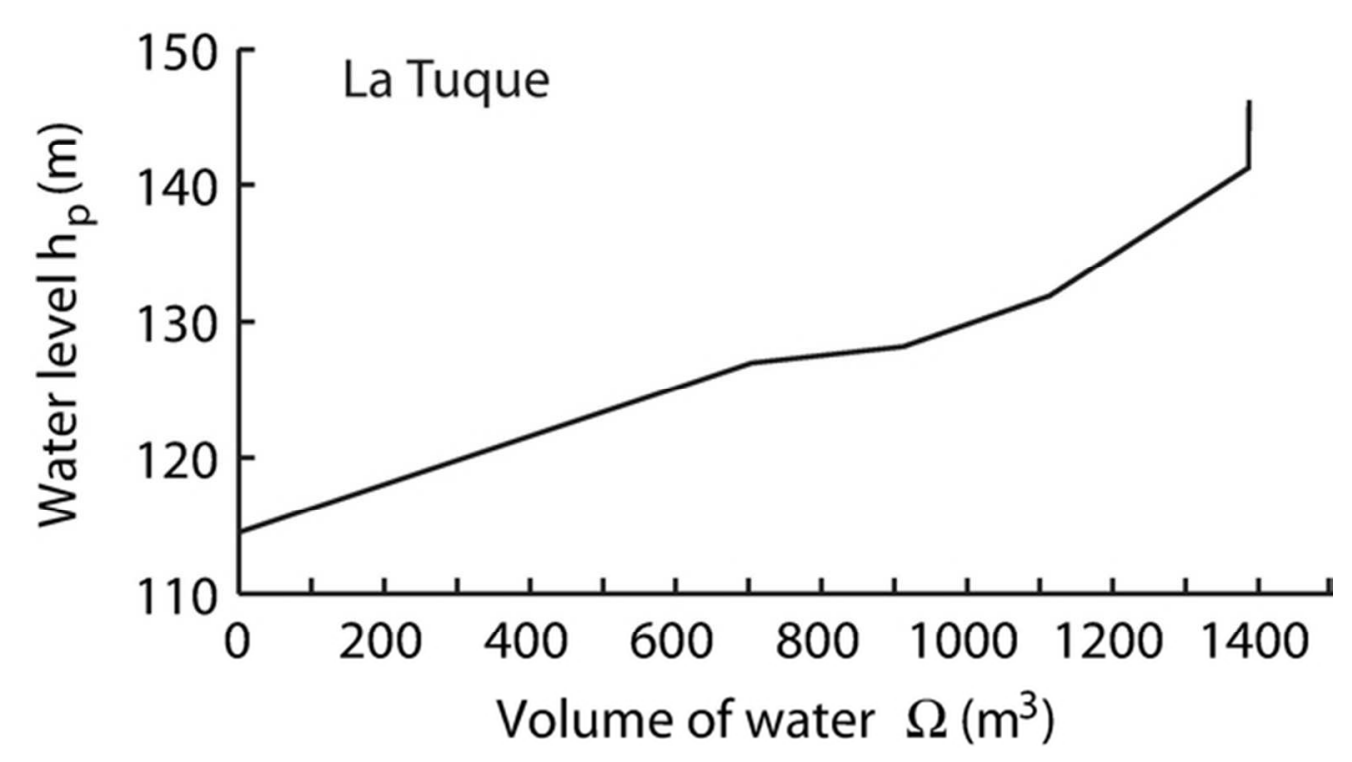

Figure 3. The volume of water versus the water level in the penstock of the La Tuque Generating Station. The water level is in reference to a historic mean sea level. (Fig. 1).

$56 \times 31 \mathrm{~mm}(300 \times 300 \mathrm{DPI})$ 

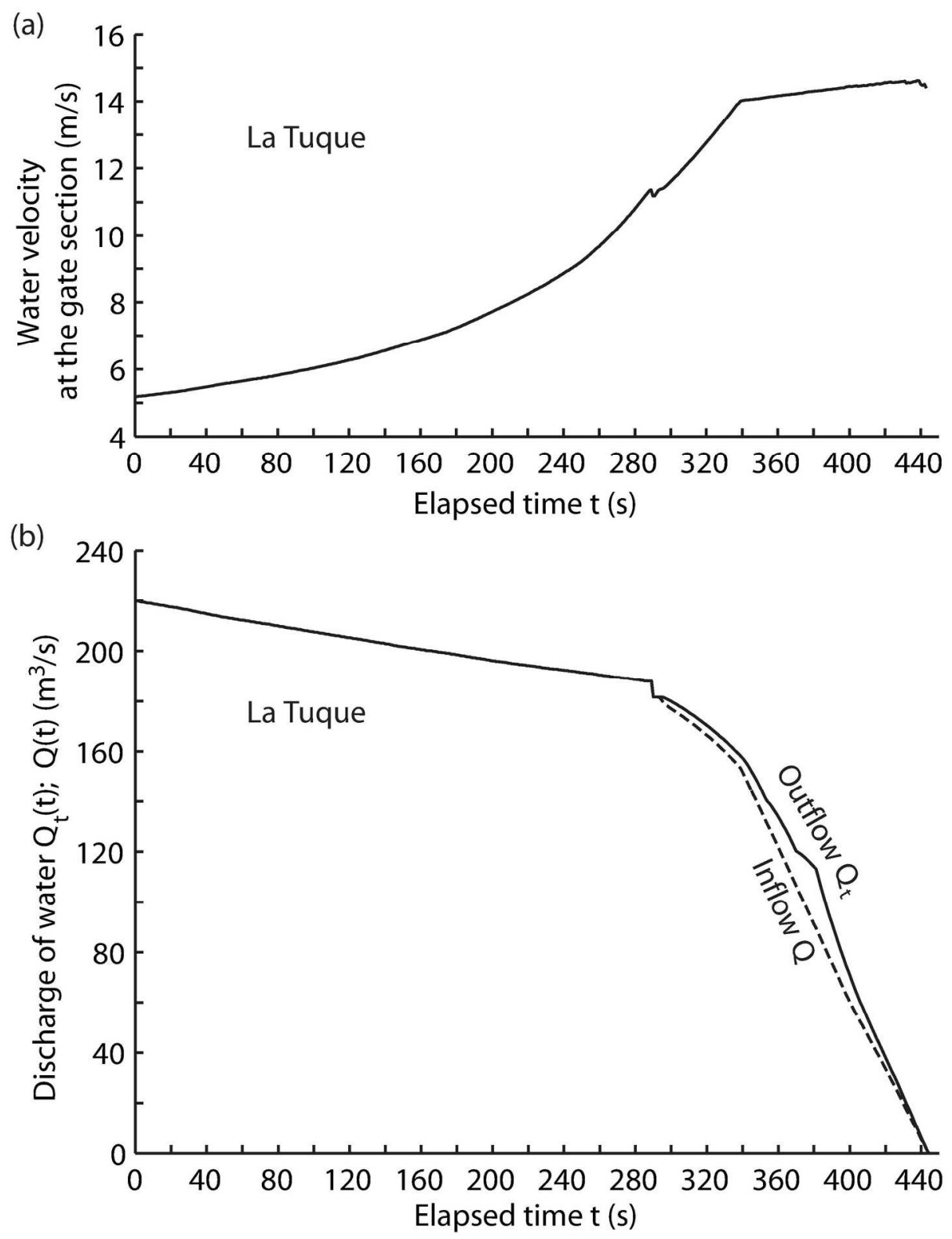

Figure 4. Time series of calculated water velocity (panel a) at the gate opening section (Fig. 1) and calculated discharge of water (panel b), during the course of gate closure. In panel (b), the dashed and solid curves are, respectively, the discharges underneath the gate to the penstock and through the turbine to the tailrace (Fig. 1). The water velocity had an initial value of $5.176 \mathrm{~m} / \mathrm{s}$ at time $t=0$, and dropped to zero at the ending time of gate closure. The two discharges had an initial value of $220 \mathrm{~m} 3 / \mathrm{s}$, and overlapped up to $t$ $\approx 290 \mathrm{~s}$.

$163 \times 215 \mathrm{~mm}(300 \times 300 \mathrm{DPI})$ 


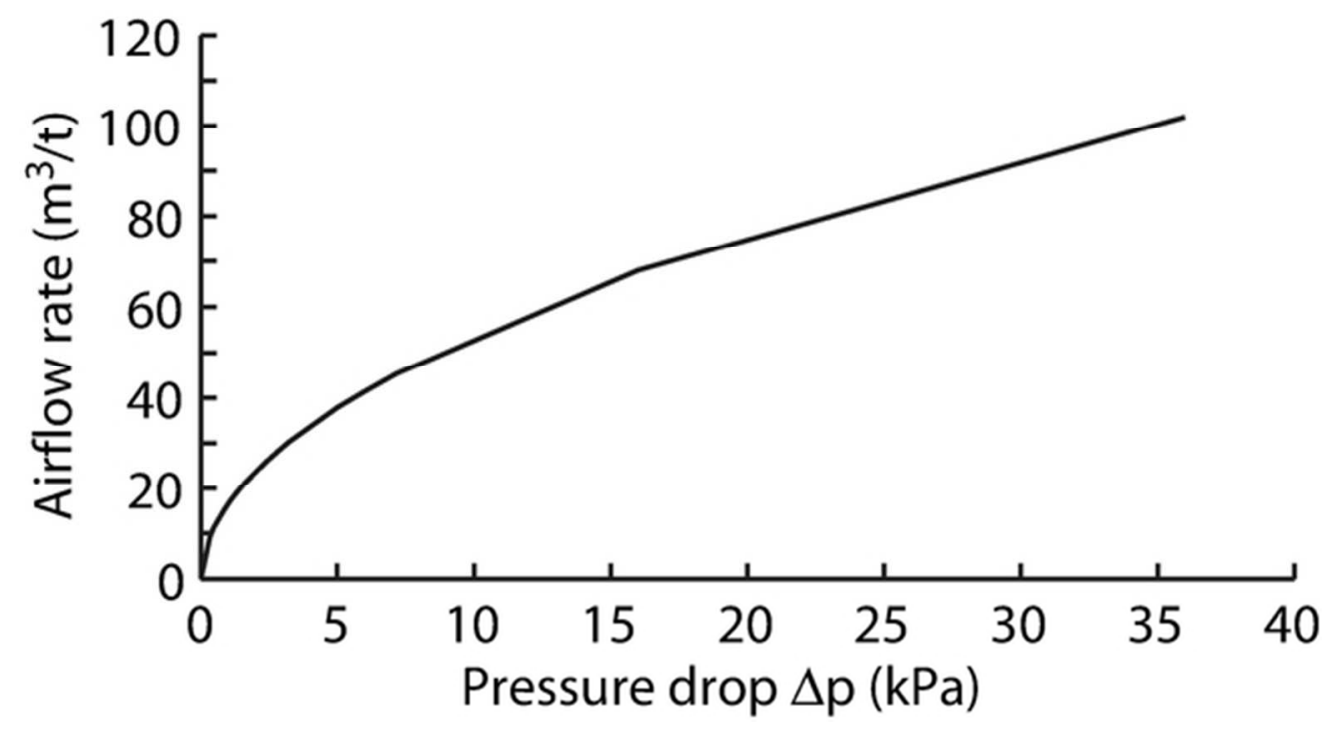

Figure 5. Relationship between air-pressure drop in the penstock and airflow rate through the air vents. $54 \times 29 \mathrm{~mm}(300 \times 300$ DPI $)$ 

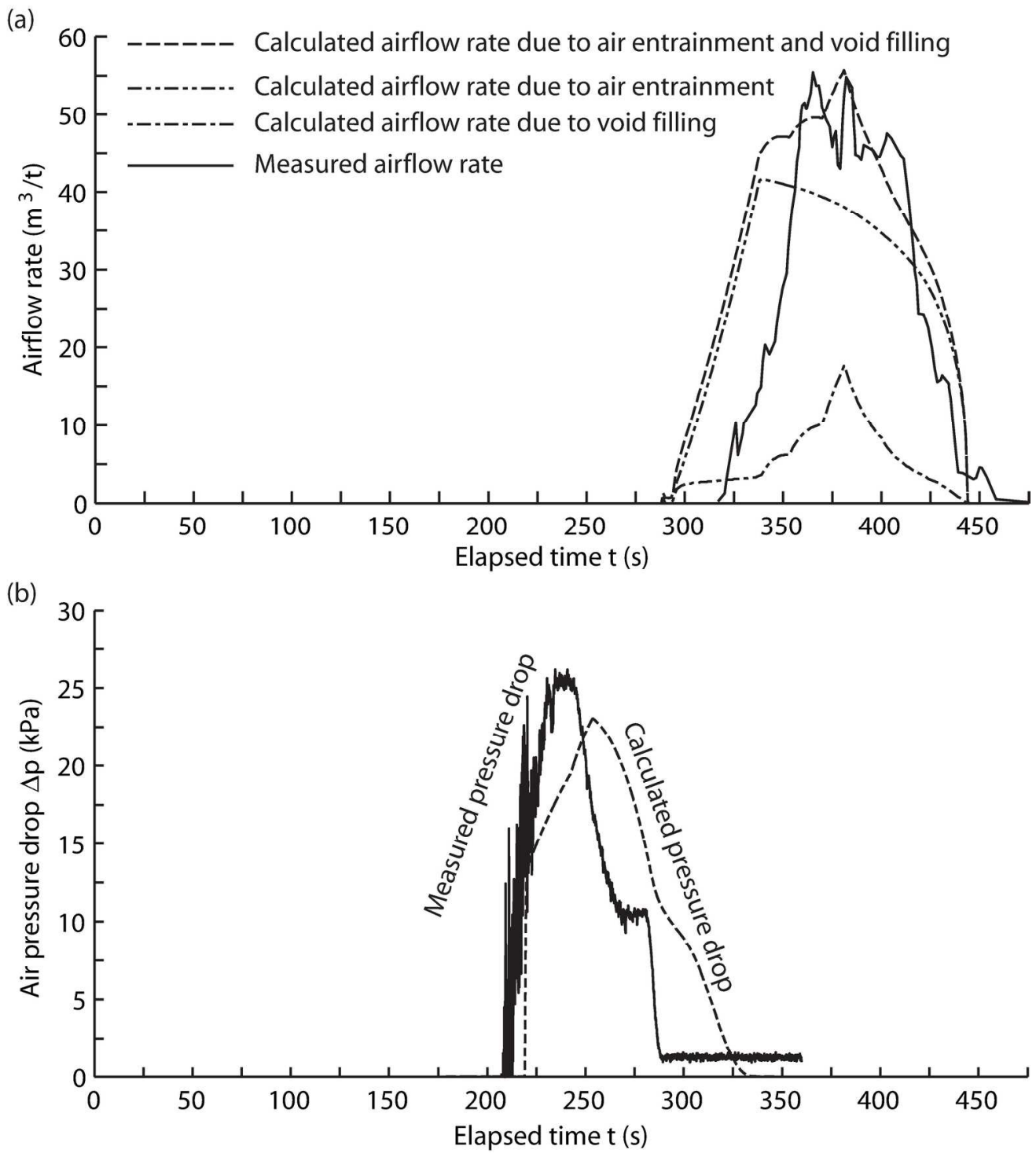

Figure 6. Comparisons of time series of airflow rate (or air demand) between measurements and calculations for the La Tuque Generating Station (panel a), and time series of air pressure drop between measurements and calculations for the Isle-Maligne Generating Station (panel b). In panel (a), the volumetric airflow rates due to air entrainment and void filling correspond to the standard atmospheric pressure. The sampling frequency of the airflow-rate and pressure-drop measurements was $10 \mathrm{~Hz}$.

$$
176 \times 197 \mathrm{~mm} \text { ( } 300 \times 300 \text { DPI) }
$$

